\title{
A bioeconomic model for Mediterranean fisheries, the hake off Catalonia (western Mediterranean) as a case study*
}

\author{
J. LLEONART ${ }^{1}$, F. MAYNOU ${ }^{1}$, L. RECASENS ${ }^{1}$ and R. FRANQUESA ${ }^{2}$ \\ ${ }^{1}$ Institut de Ciències del Mar, CMIMA-CSIC. Psg. Marítim de la Barceloneta 37-49, 08003 Barcelona, Spain. \\ ${ }^{2}$ Gabinete de Economia del Mar, Facultat de Economia, Univ. de Barcelona, Spain.
}

\begin{abstract}
SUMMARY: The theoretical aspects and the associated software of a bioeconomic model for Mediterranean fisheries are presented. The first objective of the model is to reproduce the bioeconomic conditions in which the fisheries occur. The model is, perforce, multispecies and multigear. The main management procedure is effort limitation. The model also incorporates the usual fishermen strategy of increasing efficiency to obtain increased fishing mortality while maintaining the nominal effort. This is modelled by means of a function relating the efficiency (or technological progress) with the capital invested in the fishery and time. A second objective is to simulate alternative management strategies. The model allows the operation of technical and economic management measures in the presence of different kind of events. Both deterministic and stochastic simulations can be performed. An application of this tool to the hake fishery off Catalonia is presented, considering the other species caught and the different gears used. Several alternative management measures are tested and their consequences for the stock and economy of fishermen are analysed.
\end{abstract}

Key words: bioeconomic model, Mediterranean fisheries, hake.

\section{INTRODUCTION}

Under the name of Modelling Management Strategies, a series of techniques based on stochastic simulation and computational statistics have recently been developed. The purpose of these tools is to facilitate analysis of the consequences and risks of different management measures applied to particular stocks. These techniques have been developed mainly with application to the North Atlantic in the framework of ICES (International Council for the Exploration of the Sea) and in the Southern Atlantic by Butterworth and Bergh (1993), Punt (1992, 1993) and Horwood (1994). These models consist of using a stock simulator (operating model) and a simulator

\footnotetext{
*Received December 6, 2000. Accepted March 19, 2002.
}

of the assessment process, both provided with different error sources. Using this procedure, the whole process of stock dynamics, fishing activity, fishery assessment and fishery management as an adaptive process can be simulated.

The direct application of such techniques to the Mediterranean is problematic for two reasons:

- The management of Mediterranean fisheries is carried out by means of rules such as effort limitation and other technical measures that are not periodically reviewed, while no TACs (with the notable exception of large pelagics) or any other measure implying regular assessment and adaptive management are implemented.

- The fishing activity is mainly driven by economic considerations. This is also the case in the Atlantic; however, the management by TACs limits 
the role of fishermen's decisions, at least regarding their use of the stock. The system of limiting effort in the Mediterranean allows the fishermen to develop different strategies to increase fishing mortality (Franquesa (Coord.), 1998), and therefore fishermen's decisions are included in the model.

The objectives of fisheries managers are diverse and often contradictory. They could be to maximize fishing production or revenues, to minimize catch fluctuations, to avoid the risk of collapse of the resource, to maintain employment, etc. In the case of effort control, the manager has two kinds of tools available: technical (limitation of the effort, meshes, legal sizes), and economic (subsidies, taxes, penalties). An extensive evaluation of the effect of these economic measures is available in OECD (2000). The effectiveness of each of these tools in achieving the manager's purpose varies. In a complex system, as fisheries can be, it is not always evident what will be the response from the system to a certain management measure. Furthermore, predictions of the indirect effects of a certain measure are still more uncertain.

There is evidence that some important resources of the Mediterranean are clearly overexploited: e.g. hake (Aldebert et al. 1993, Aldebert and Recasens, 1996), or are exposed to a non-optimal exploitation: e.g. anchovy (Pertierra and Lleonart, 1996). Building the stock to sustainable levels, probably giving higher yield, implies overcoming a short-term crisis. The evaluation of the biological and economic consequences of the various alternative transition processes to bring about recovering a stock should be an interesting issue for the decision-maker.

The final users of the product are three: the scientist, the decision-maker, and the fisherman. For the scientist, the present model constitutes a research tool that should lead to an improved understanding of the mechanisms by which the fisheries system operates. It can also be an advisory tool, as the model acts as a test bench for analysing different management options, decision risks, sensibility of the parameters, etc. In addition, it identifies the fundamental parameters.

For the administrators and decision-makers, the model offers a way to assess the economic and biological effects of particular management measures (technical, economic or both) in the short and mid term. This could be very useful in the design of policies for mid-term objectives and for exploring different ways to attain them. It is also important that the administrators realize the extent to which the fishery depends on the dynamics of a biological resource and not only on economic decisions.

The model offers fishermen and managers a new perspective on the behaviour of the system, including its temporal scale. The model should contribute to an increased comprehension of the usefulness or uselessness of certain management measures, and establish the difference between short and mid term regarding earnings and losses.

In order to analyse the applicability of the Modelling Management Strategies to Mediterranean fisheries, research started in 1994 within the framework of the EU Directorate General XIV funded project "Quantitative Analysis of the Relationships which condition the North Occidental Mediterranean Fishing System" (acronym: Heures) (Franquesa (Coord.), 1998; Franquesa, 1996). Later, a project, M5, funded by the Spanish Agency for the Science and Technology (CICYT) allowed us to proceed further in the elaboration of the model. A software package has been developed complementing the conceptual model. There are two versions: the analytical model (MEFISTO), and a simplified version using the global approach (or production method) for the stock box (MECON) with formative and pedagogical objectives.

\section{MODEL FUNDAMENTALS}

The objective of the model is to reproduce the fishing conditions characteristic of the Mediterranean, including several aspects that differentiate it from the models elaborated for the Atlantic fisheries. The most important particularities are:

- The model should necessarily be bioeconomic to accommodate the dynamic nature of living resources, and at the same time the economic relationships that govern Mediterranean fisheries.

- Management is mainly based on effort control, although other technical and economic measures exist.

- The management system is non-adaptive. No regular assessments are done and hence no adaptive management policy is implemented. TACs don't exist and the economic administrative tools acquire as much importance as the technical tools.

- Increasing "catchability" (in effect, efficiency) is the mechanism of increasing fishing mortality by the fishermen: they cannot increase fishing effort, as defined by law in the Mediterranean area, i.e. via fishing time and installed power. Therefore they 
will always try to maximize fishing mortality. The only mechanism available to fishermen to increase catch without increasing nominal effort is to increase catchability by means of investment in technology. An essential point of the model is the exploration of catchability as a function of the installed capital and time. Smit (1996) recognized that the potential fishing capacity of a vessel can be measured as the gross proceeds of the vessel. If the investment is related to the proceeds, we propose that the total investment in the vessel (capital) is related to the fishing capacity (catchability). In accordance with this hypothesis, a bioeconomic model, rather than a biological one, is the more appropriate to simulate the Mediterranean fishery, since it is in certain measures self-managed by the fishermen through economic mechanisms.

- It is multispecies, multigear, and multifleet.

The model has been built in a modular way on a system of "boxes." A total of three boxes are defined:

- The stock box. This simulates the dynamics of a particular stock. The input is the fishing effort and the catchability (output of the fisherman's box) whose product constitutes the fishing mortality applied to the stock. The output is the catch that goes into the market box. The stock box can have diverse simultaneous boxes (multispecies). There are species of two kinds: the main species, whose dynamics are completely explicit, and the secondary species, whose dynamics are not known but whose yields are computed as a function of those of the main species.

- The market box. This converts the catch for each main species and secondary species into money with specified price functions. One has to consider the base price, the size of fish, and the amount of the fish offer on the market.

- The fishermen box. This simulates the fisherman's economic behaviour. The input is the money produced in the market box. The output is the effort (within a maximum limit set by the legislation) and the catchability, over which the fisherman has certain control as function of the vessel's capital. The parameters of the fishermen box are contained at different levels: country, fleet, and boat. The level country contains the most general economic parameters that embrace diverse fleets (such as cost of fuel). The level fleet contains the technical and economic parameters characteristic of each fleet (initial vectors of catchability and fishing mortality, GT, initial capital, etc.). Finally, the last level, vessel, allows particularisation of the characteristics of each boat (vessel specific costs, capital and catchability).

The simulations forward in time are conducted by carrying a complete cycle in each time unit. The profits of the last time unit revert in the fishing activity of the boat in the following time unit. Contrary to the Atlantic models, we don't include any assessment box.

The operation of the model also has the following characteristics:

- The unit of time of the simulation process and that of presentation of results can be specified as week, month, quarter or year.

- The analysis can be deterministic or stochastic.

The values of certain parameters can be modified at different moments of the simulation ("events") for the purpose of simulating administrative actions.

\section{The stock box}

The stock box simulates the dynamics of the resource and uses the standard equations of population dynamics. See notation in Table 1. The model is multispecies and it admits two types of species: main species, with well-known dynamics, and secondary species whose dynamics are defined in relation to those of the main species. The model is structured by fish age, $a$, and gear, $g$.

The fishing mortality at age $a$ generated by a gear $g$ is defined as

$$
F_{a g}=S_{a g} \cdot E_{g} \cdot q_{a g}
$$

where $S_{a g}$ is the selectivity factor accounting for the interaction gear-fish, $E_{g}$ is the effort applied by the gear $g$, and $q_{a g}$ the catchability that corresponds to the gear $g$ and the age $a$, (at time $t$ and for capital $K$, not explicitly shown for brevity).

The total fishing mortality corresponding to age $a$ is:

$$
F_{a}=\sum_{g}^{G} F_{a g}
$$

and the total mortality corresponding to age $a$ is

$$
Z_{a}=F_{a}+M_{a}
$$

where $M_{a}$ is the instantaneous natural mortality rate at age $a$.

The dynamics of the number of individuals of a cohort responds to the following equation: 
TABLE 1. - Notation. M: mass, L: length, T: time, MU: monetary units

\begin{tabular}{|c|c|c|c|}
\hline symbol & & units & $\operatorname{dim}$ \\
\hline $\bar{N}$ & mean number of individuals & indiv. & - \\
\hline$\overline{\boldsymbol{B}}$ & mean biomass & ton & M \\
\hline $\bar{w}$ & mean individual weight & $\mathrm{g}$ & M \\
\hline \multirow[t]{3}{*}{$\alpha$} & parameter of the stock-recruitment relationship: & & \\
\hline & $\mathrm{B} \& \mathrm{H}$ model & & - \\
\hline & Ricker's model & $\operatorname{ton}^{-1}$ & $M^{-1}$ \\
\hline$\beta$ & parameter of the stock-recruitment relationship & $\operatorname{ton}^{-1}$ & $\mathrm{M}^{-1}$ \\
\hline$\tau$ & parameter in the captial-catchability relationship & & - \\
\hline \multirow[t]{3}{*}{$\mu$} & parameter in the revenue-catch relationship for secondary species & & \\
\hline & (additive model) & $€$ & MU \\
\hline & (multiplicative model) & $€ \cdot \operatorname{ton}^{-v}$ & $\mathrm{MU} \cdot \mathrm{M}^{-v}$ \\
\hline$v$ & parameter in the revenue-catch relationship for secondary species & & - \\
\hline$\gamma_{1}$ & reference price. parameter in the price model & $€ / \mathrm{kg}$ & $M U \cdot M^{-1}$ \\
\hline$\gamma_{2}$ & size-price modifier. parameter in the price model & & - \\
\hline$\gamma_{3}$ & offer-price modifier. parameter in the price model & & - \\
\hline$a$ & age & year & $\mathrm{T}$ \\
\hline A & parameter in the length-weight relationship & $\mathrm{g} / \mathrm{cm}^{\mathrm{B}}$ & $\mathrm{M} \cdot \mathrm{L}^{-\mathrm{B}}$ \\
\hline$B$ & parameter in the length-weight relationship & & - \\
\hline $\boldsymbol{B}$ & biomass & ton & M \\
\hline E & effort & hours.day & $\mathrm{T}$ \\
\hline$C$ & catch & ton/year & $\mathrm{M} \cdot \mathrm{T}^{-1}$ \\
\hline$C 1$ & Trade cost & $€ /$ year & MU.T ${ }^{-1}$ \\
\hline$C 2$ & Daily cost & $€ /$ year & MU.T ${ }^{-1}$ \\
\hline C3 & Labour cost & $€ /$ year & $M U \cdot T^{-1}$ \\
\hline C4 & Compulsory cost (inevitable to remaining in the activity) & $€ /$ year & $\mathrm{MU} \cdot \mathrm{T}^{-1}$ \\
\hline C5 & Maintenance cost & $€ /$ year & $\mathrm{MU} \cdot \mathrm{T}^{-1}$ \\
\hline C6 & Opportunity cost & $€ /$ year & $M U \cdot T^{-1}$ \\
\hline$C 7$ & Financial cost & $€ /$ year & MU.T ${ }^{-1}$ \\
\hline $\mathrm{Ca}$ & Part of maintenance cost avoidable & $€ /$ year & $M U \cdot T^{-1}$ \\
\hline ca & $\%$ of the maintenance cost that is avoidable & & \\
\hline$i$ & vessel index & & \\
\hline$K$ & capital & $€$ & MU \\
\hline$K_{0}$ & initial capital & $€$ & MU \\
\hline$k$ & growth rate in the von Bertalanffy growth model & year $^{-1}$ & $\mathrm{~T}^{-1}$ \\
\hline$l$ & length & $\mathrm{cm}$ & $\mathrm{L}$ \\
\hline$L_{\infty}$ & maximum length in the von Bertalanffy growth model & $\mathrm{cm}$ & $\mathrm{L}$ \\
\hline$M$ & natural mortality rate & year $^{-1}$ & $\mathrm{~T}^{-1}$ \\
\hline$m$ & maximum age & year & $\mathrm{T}$ \\
\hline$M M$ & monte menor & $€$ & MU \\
\hline$N$ & number of individuals & indiv. & \\
\hline$O$ & offer & ton & M \\
\hline$p$ & price & $€ / \mathrm{kg}$ & $\mathrm{MU} \cdot \mathrm{M}^{-1}$ \\
\hline$q$ & catchability & day $^{-2}$ & $\mathrm{~T}^{-2}$ \\
\hline$Q_{0}$ & initial catchability & day $^{-2}$ & $\mathrm{~T}^{-2}$ \\
\hline$R$ & recruitment & indiv. & \\
\hline$R T$ & total revenue & $€ /$ year & $\mathrm{MU} \cdot \mathrm{T}^{-1}$ \\
\hline$S$ & selectivity & & - \\
\hline$S S B$ & spawning stock biomass & ton & M \\
\hline$t$ & time & year & $\mathrm{T}$ \\
\hline$t_{0}$ & age at length 0 in the von Bertalanffy growth model & year & $\mathrm{T}$ \\
\hline$w$ & individual weight & $\mathrm{g}$ & M \\
\hline$Y$ & revenue & $€ /$ year & MU.T ${ }^{-1}$ \\
\hline$Z$ & total mortality rate & year $^{-1}$ & $\mathrm{~T}^{-1}$ \\
\hline
\end{tabular}

$$
N_{a+1, t+1}=N_{a t} \exp \left(-Z_{a t}\right)
$$

where $N_{a t}$ is number of individuals of age class $a$ at the beginning of the time $t$. Since the age $a$ and the time $t$ are measured in the same units, an individual of age $a$ in time $t$ will have age $a+1$ in time $t+1$.

The average number of individuals during the age-class interval $a$ is:

$$
\bar{N}_{a}=N_{a} \frac{1-\exp \left(-Z_{a}\right)}{Z_{a}}
$$

The von Bertalanffy growth model is assumed:

$$
l_{a}=L_{\infty}\left(1-\exp \left(-k\left(a-t_{0}\right)\right)\right)
$$

and the relative growth in weight is:

$$
w_{a}=A \cdot l_{a}^{B}
$$

With the mean weights by age, the mean biomass by age can be calculated:

$$
\overline{\boldsymbol{B}}_{a}=\bar{N}_{a} \bar{w}_{a}
$$


The total mean biomass for the whole stock is

$$
\overline{\boldsymbol{B}}=\sum_{a=1}^{m} \overline{\boldsymbol{B}}_{a}
$$

The catches are also calculated by gear:

$$
C_{a g}=F_{a g} \overline{\boldsymbol{B}}_{a}
$$

The total catch by age, gear and both are, respectively:

$$
C_{a}=\sum_{g}^{G} C_{a g}, C_{g}=\sum_{a}^{G} C_{a g} \text { and } C=\sum_{a}^{m} \sum_{g}^{G} C_{a g}
$$

To carry out the simulations we are required to model the recruitment $\left(N_{1}\right)$. Except for the case of constant recruitment, the number of recruits is a function of the spawning stock biomass $(S S B)$ that is calculated from the proportion of mature fish by age $\left(I_{a}\right)$ of the mean biomass:

$$
\begin{gathered}
S S B_{a}=\overline{\boldsymbol{B}}_{a} I_{a} \\
S S B=\sum_{a}^{m} S S B_{a}
\end{gathered}
$$

Three different procedures for generating recruits are used:

- constant recruitment, where for each simulation the same number of recruits $N_{1}$ (constant) is generated;

- Beverton and Holt's model:

$$
N_{1}=\frac{1}{\alpha+\beta S S B}
$$

- and Ricker's model

$$
N_{1}=\alpha S S B e^{-\beta S S B}
$$

\section{The function of catchability}

The input to the stock box and the output from the fishermen box are the fishing effort $E_{g}$ vector and the catchability $q_{a g}$ matrix. Since the maximum fishing effort is limited by Mediterranean fisheries legislation, the mechanism whereby fishermen increase $F$ is by increasing catchability. There are a large number of elements that relate fishing effort with fishing mortality, and they are all contained within catchability. Laurec and Le Guen (1981) give the following outline:

1) availability: depends on the fish and on the fishing gear and is independent of the fisherman's behaviour.

a) accessibility: geographical component, displacement from and to the fishing areas. b) vulnerability: related to fish behaviour.

2) efficiency: this depends, among other factors, on the fishing strategy or fishing tactics.

Of all these elements, the one that the fisherman clearly can modify is efficiency for one particular gear (we exclude gear changes in our model). That depends on, among other things, technological progress, and this is modelled here as a function of capital (more investment results in increased fishing efficiency) and of time (technological progress improves with time and becomes more affordable). Our modelling approach is outlined as follows:

We assume the following equation to express $q_{t, K}$, the catchability as a function of time $t$ and capital $K$.

$$
q_{t, K}=Q_{0} \tau^{t} \frac{1-e^{-h K}}{1-e^{-h K_{0}}}
$$

for $K_{0} \neq 0$ and $h \neq 0$, where $\tau$ and $h$ are parameters, and $Q_{0}$ and $K_{0}$ are the initial catchability and the initial capital (at $t=0$ ) respectively.

To make $q_{t}$ constant, and equal to $Q_{0}$, it is necessary that $\tau=1$ and $h \rightarrow \infty$.

To make $q_{t}$ only depend on time it is necessary that $\tau \neq 1$ and $h \rightarrow \infty$. To make $q_{t}$ increase at an annual $\mathrm{p} \%, \tau=1+\mathrm{p} / 100$. If $\tau<1$ the catchability decreases with time.

To make $q_{t}$ only depend on capital it is necessary that $\tau=1$ and $h>0$, but not $h>>0$ (in order for the effect to be seen, $h \cdot K$ should be smaller than 5 and is recommended to be of the order of 1). Maximum catchability (for "infinite" capital) is

$$
Q_{0} /\left(1-\exp \left(-h \cdot K_{0}\right)\right) \text {. }
$$

Thus, the two parameters have the following meaning:

$\tau$ (condition: $\tau>0$, reasonable $\tau \geq 1$ ) Expresses the dependence on time, for example if we assume an annual catchability growth of $2 \%, \tau=1.02$. If $\tau=1, q$ is independent of time.

$h$ (condition: $\mathrm{h}>0$ ). This is a modifying influence of capital in the calculation of catchability. If $h$ is high, capital doesn't affect catchability. If $h$ is very near 0 the weight of capital is substantial (even excessively so).

\section{Multispecies}

The model is multispecies, admitting two classes or types of species: the main species and the associate, or secondary, species. In either case only technical interactions are envisaged by the model, 
not ecological interactions (such a predation or competition).

The main species are defined as those whose dynamics are known so they can be simulated with the equations expressed previously. The secondary species are a pool of species that are significant to the fishery from an economic point of view (as accompanying species or associated with a main species), but whose population dynamics are unknown. We assume an empirical relationship of the associated species with the main species in one of the two following ways, the multiplicative model:

$$
Y=\mu \cdot C^{v}
$$

or the additive model:

$$
Y=\mu+v \cdot C
$$

where $\mu$ and $v$ are parameters, $C$ is the catch of the main species, and $Y$ are the revenues yielded by the secondary species. $\mu$ and $v$ can be derived from actual catch data. $v$ denotes the correlation between the catch of the main species and the economic yield of the secondary species; hence when $v>0$ the revenues obtained from the secondary species grows with increasing catch of the main species. When $v$ $<0$ then the reversal holds true and when $v=0$ then the secondary species is independent from the main species to which it is associated. $\mu$ is a scale parameter, which also holds the conversion of catch to revenue units.

\section{The market box}

The total revenues of a gear are calculated according to

$$
R T_{g}=\sum_{a=1}^{m}\left(p_{a} C_{a g}+Y_{a g}\right)
$$

where $p_{a}$ is the unit price of age- $a$ catch. This price is calculated following the market law (Lleonart $e t$ al., 1996):

$$
p_{a}=\gamma_{1} \bar{w}_{a}^{\gamma_{2}} O^{\gamma_{3}}
$$

where $O$ (the offer on the market) is the sum of catch $C$ plus any imports of this species. This model is extremely simple to facilitate its practical use. Models such as Peredy et al. (2000) that consider 146 related products for the computation of price are not applicable in this context. In fact, the application of our model is similar to Lee et al. (2000), but allows to introduce more information when the data are available. The $\gamma$ are parameters: $\gamma_{1}$ is a price parameter when the price is not affected by fish size or offer, $\gamma_{2}$ the size-price modifier (it will usually be positive with larger sizes fetching higher prices) and $\gamma_{3}$ the price-offer modifier (it will usually be negative, with larger offer resulting in lower prices). If $\gamma_{2}=0$, the price is independent of the weight; if $\gamma_{3}=0$ the final price is independent of the offer (i.e. the market doesn't influence the price of the product). These three parameters can be obtained by an empirical regression if data on prices by weight and total supply (including imports) are available. Given that prices are not given for age classes in Catalonia and that we do not consider imports in the present work, we take $\gamma_{1}$ as the average price (constant) and $\gamma_{2}, \gamma_{3}$ equal to 0 .

\section{The fishermen box}

The operation of the fishermen box is represented in Figure 1, which shows the relationships between the different variables of this part of the model.

The fishermen box converts total revenues to the fishing effort that will be applied by the gear in the following unit of time, measured in number of fishing days $\mathrm{x}$ hours $\left(E_{g}\right)$, catchability of this fishing gear $\left(q_{a g}\right)$, and selectivity factor.

The assumptions basic to the fisherman's box are

- The fisherman assumes that the production depends on the effort and catchability applied. Catchability is a function of capital and time.

- The revenues at the end of one period are used to cover the different costs of the fishing activity for the next period. Investment is a function of profits.

- There is a maximum legal limit for number of days at sea. The number of ships, as well as their power, is also limited by the administration.

- The fisherman intends to go fishing for the maximum number of days that the law and revenues allow. A large body of literature reports that only effective institutional controls (provided by the administration or by the fishermen organisations) can result in a reduction of effective fishing time. If this control is not effective in Mediterranean conditions (high price, reduced catch, weak financial capacity and nearness of fishing grounds) the total fishing time is all the time technically possible (including summer holidays and Sundays). 


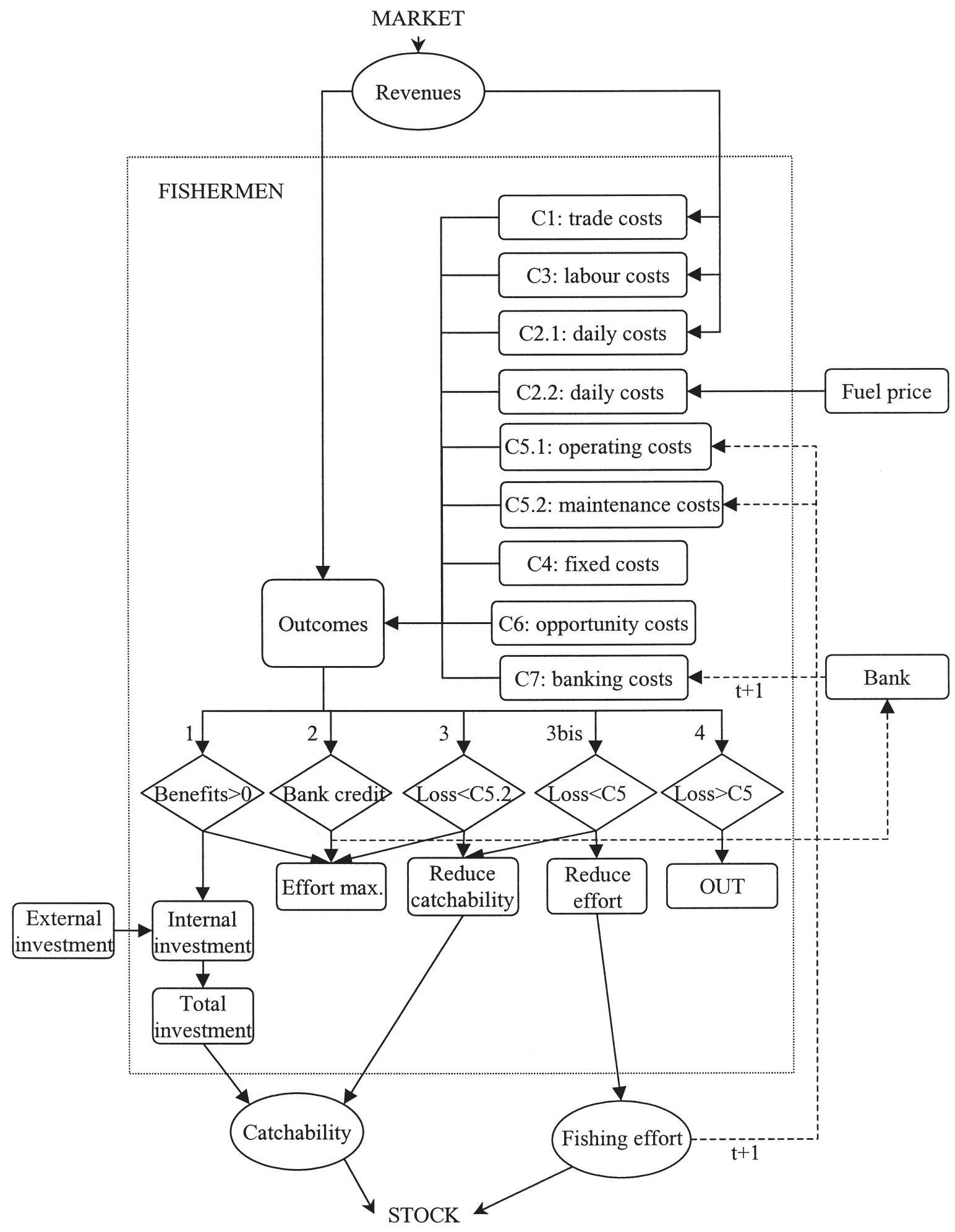

FIG. 1. - Cost structure and decision analysis of the fisherman box

For the analysis of costs, we use the methodology adopted to produce the Annual Economic Report of European Union Fisheries (2000), applied to the specific conditions of the Mediterranean. The expenses that the fishermen should meet are divided into 7 groups (Table 2):

C1 Trade cost. All costs that are possible to express as a percentage of the Total Revenues for the 
TABLE 2. - Cost analysis by vessel.

\begin{tabular}{|c|c|c|c|c|}
\hline \multirow[t]{2}{*}{ Short-term costs } & Variable costs & $\begin{array}{l}\text { Trade costs } \\
\text { Labour costs } \\
\text { Daily costs }\end{array}$ & $\begin{array}{l}\mathrm{C} 1 \\
\mathrm{C} 3 \\
\mathrm{C} 2\end{array}$ & $\begin{array}{l}\text { function of catch } \\
\text { function of effort } \\
\text { function of effort }\end{array}$ \\
\hline & Fixed costs & $\begin{array}{l}\text { Maintenance costs } \\
\text { Compulsory costs }\end{array}$ & $\mathrm{C} 5$ & $\begin{array}{l}\text { function of profits }{ }^{(1)} \\
\text { constant }{ }^{(2)} \\
\text { constant }\end{array}$ \\
\hline Long-term costs & & $\begin{array}{l}\text { Opportunity costs } \\
\text { Financial costs }\end{array}$ & $\begin{array}{l}\text { C6 } \\
\text { C7 }\end{array}$ & $\begin{array}{l}\text { price of money } \\
\text { interest rates }\end{array}$ \\
\hline
\end{tabular}

a part of the maintenance costs is function of benefits. These costs are devoted to improvement of the vessel (increases capital) and are avoidable

${ }^{2}$ a part of the maintenance costs are held constant and represent a minimum unavoidable maintenance of the vessel.

vessel $i\left(R T_{i}\right)$. (VAT, Fishermen's association taxes, labour taxes, local taxes, sale process, etc.) This is a percentage of the total of the Total Revenues $\left(R T_{i}\right)$ :

$$
C 1_{i}=c 1_{g} \cdot R T_{i}
$$

We consider $c l_{g}$ to be the same for each group of vessels (fleet)

C2 Daily costs. These are the costs caused by the fishing activity (fuel $(C C)$, net mending, daily food expenses, etc.), excluding labour cost. They are a function of fishing effort (the time of fishing: days $\mathrm{x}$ hours) and include a part of maintenance costs, such as net mending, which are proportional to effort (C2.1). For each vessel $i$ we consider

$$
C 2_{i}=c 2_{i} \cdot E_{i}
$$

When the initial $R T$ is reduced by $C 1$ and $C 2$, what remains is known in Spain as "monte menor" $(M M)$ :

$$
M M=R T-C 1-C 2
$$

$M M$ is divided in parts, one for the owner, and another for the crew (including the owner, when the owner is a worker). The crew part is a percentage that can vary among fleets but averages around 50\% $\left(c 3_{g}\right)$, once the trade costs and the daily costs have been deducted.

C3 Labour costs. These are composed of the share $\left(c 3_{g}\right)$ corresponding to the crew in function of $M M$

$$
C 3_{i}=c 3_{g}\left(R T_{i}-C 1_{i}-C 2_{i}\right)
$$

It is also possible to obtain the average wage for each group of vessels as

$$
\mathrm{AW}_{g}=C 3_{g} / \text { crew number }
$$

C4 Compulsory costs (harbour costs, license, insurance, etc.). Yearly costs incurred by the fisherman for keeping his business legal. We suppose that they are constant. They are not dependent upon effort. They are considered to be an exogenous variable in the model and are expressed per vessel.

C5 Maintenance costs (flexible costs). These are the costs required to maintain the fleet at its maximum performance level. They are included in the reinstatement of the used capital, repairs, etc. They are considered as an exogenous variable in the model and are expressed per vessel.

C5 is divided in two parts by a percentage per vessel. The first part is the operating costs that are indispensable to meet to remain in activity. The second part is the other maintenance costs, that is avoidable $(\mathrm{Ca})$ but lack of maintenance may reduce the catchability (painting, maintenance of electronic devices, maintenance of engine, etc.). This percentage $(c a)$ is also considered per vessel.

C6 Opportunity cost. This is the cost of using the capital invested. It is a function of the capital invested $(I)$ and the rate of the "Public Debt" $(c \sigma)$. It allows the determination of what the capital's alternative profitability would be if it were invested elsewhere for a fixed term. It indicates the revenues lost (or "opportunities" lost) to the fisherman by investing in the fishing activity. This rate is fixed by country.

$$
C \sigma_{i}=c \sigma_{c} \cdot I_{i}
$$

C7 Financial cost. Interest and capital return on bank loans. In case of negative profits, debts arise and any further investment necessitates bank loans. $C 7$ depends on banking interest rates $(c 7)$ and the individual debt $\left(D_{i}\right)$ incurred. 


$$
C 7_{i}=c 7 D_{i}
$$

$D_{i}$ has an upper limit (maximum debt accepted by banks) depending on the total capital invested, as the bank is not willing to lend more than $d_{m} \cdot K_{i}$, where $d_{m}$ is a maximal percentage of lend authorised by the bank, and $K_{i}$ the total vessel investment.

\section{The fishermen's decisions}

Regarding the fishermen's "financial health" after one time-unit period, there exist four possible results. We model the fishermen's priorities in response to these results, so as to meet the expenses derived from the fishing activity after having met the unavoidable costs. (If either the fisherman cannot meet the unavoidable costs or the dismissal price is higher than the current vessel value, the vessel goes out of the fishery).

\section{$1{ }^{\text {st }}$ Positive Profits}

The profits in the model are totally reinvested. There exists a technical limitation establishing a restriction, which determines how much of the catchability is increased by a new introduction of investment. This limitation is incorporated in the catchability modifier. The profits explain a part of investment (the Internal Investment, $I_{i}$ ), but the total investment is also affected by subsidies. Then the total investment $(I)$ is defined as:

$$
I=I_{i}+I_{e}
$$

where $I_{e}$ are the subsidies that the fishing sector can receive from institutions (External Investment). However, the destination of investment is conditioned in the model, just as it is in the Mediterranean reality, where there is a maximum number of ships that can be based at a port, a maximum number of days of fishing, etc. The fisherman can invest to improve the catchability of the boat and fishing gear by acquiring fish detection systems, navigation aids, improving fishing machinery, modernizing the ship, etc. In our sense, investment is a concept restricted to the possibility of improving catchability and not extending to the possibility of increasing effort (as time at sea and number of vessels) beyond a maximum level set by the legislation. Investment in the present period influences catchability across the fleet in the following period through variation in total fleet capital.
The value of the capital of the fleet increases with the investments. The result of positive profits is, therefore, to increase in the following period catchability for the gear that has obtained them, while maintaining fishing effort at its maximum levels.

\section{$2^{\text {nd }}$ Negative Profits (losses), but bank credits are still available}

In the case of negative profits, the fisherman shall try to maintain the same level of activity by borrowing money from the bank. The new loan has to be added to non-redeemed loans of previous years, if any. The total debt incurred with the bank is always limited to a percentage of the value of the capital $\left(d_{m}\right)$, as banks lend money on a personal guarantee. In the model, this guarantee is the value of the ship, but the bank (as in any mortgage) does not accept as guarantee something that has the same value as the loan. When this limit is exceeded, the possibility of obtaining new loans disappears, and we must examine the $3^{\text {rd }}$ possibility, below.

If credit is obtained, the result is that the catchability and the effort are maintained, but the following year a new added cost will exist: the financial cost (C7), which is unavoidable.

$3^{\text {rd }}$ Negative Profits (losses), it is not possible to borrow more money, but the unavoidable costs can still be met

If the fisherman cannot cover the costs and can no longer borrow money to maintain maximum catchability and fishing effort, he will have to reduce other costs.

In this case, the fisherman will reduce all the costs that are avoidable in the short term: the avoidable part $(\mathrm{Ca})$ of maintenance costs $(\mathrm{C} 5)$ in the first place. This will consequently reduce the maintenance, and thus the catchability, but still maintain maximum effort. The maintenance costs (C5) are necessary to maintain the ship in top operative condition. If these costs cannot be covered the value in capital of the fleet decreases and the catchability falls.

The fisherman will try to fish the legal maximum of days, but if his losses are larger than the avoidable maintenance costs he will be forced to reduce other costs, the only option being to reduce the variable daily costs $(C 2)$. In this way, by consuming less fuel the fisherman is being forced to reduce fishing effort 
(in fishing days) so as to limit the variable daily expenses incurred.

\section{$4^{\text {th }}$ Negative Profits (losses) and unavoidable costs cannot be met}

If losses become larger than the avoidable costs $(C 2+C a)$, the fisherman can no longer make it in the face of these unavoidable expenses and he ceases fishing. In this case, not only the catchability decreases but also the effort, and the ship or fleet - disappears from the fishery. The decrease of fishing mortality will profit the remaining ships or fleets.

\section{The time scale}

This is a step-by-step model, therefore the time unit needs to be defined. The complete process takes place in a unit of time: for example, if the unit of time is a year, this represents that the fisherman fishes, goes to the market, and makes decisions once in a year, i.e. once in each unit of time. The program admits the following time scales: week, month, quarter or year.

The fish age is measured in the same units as the time. The time scale has implications for several aspects of the definition of the work scenario, in particular for recruitment. The simulation results can be shown at the time scale at which the simulation has been carried out, or at a larger scale: for example, it is possible to carry out the simulation at a weekly time scale and present the results annually.

\section{The simulation}

The objective of the model is to carry out projections starting from the current situation forwards into the future with the purpose of analyzing the behaviour of the fishery under different conditions, particularly different management situations.

It will then project into the future the fishery over a certain number of time units. This projection can be deterministic or stochastic.

In the deterministic simulation the parameters have a fixed value set up by the user, and the projection is carried out using these values. The results are fixed values.

The stochastic simulation seeks to analyze the effects of uncertainty of one or several parameters. Such parameters are provided with a stochastic error term and the simulation is carried out many times.
The results are probability distributions rather than fixed numbers. Three types of errors are considered:

- Uniform additive error. A random uniform distributed variable is added to the parameter. The user should set up the variation interval.

- Normal distributed additive error. A random normal distributed variable is added to the parameter. The mean is 0 and the user should set up the variance.

- Lognormal multiplicative error. A random lognormal distributed variable is multiplied by the parameter. The mean is 1 and the user should set up the variance.

\section{Events}

Along the units of time that are projected, it is possible to introduce events (generally consisting of administrative measures) in any time unit.

\section{Initial conditions}

The program start-up requires, besides the parameters, the establishment of an initial stock situation. This implies having the vectors of mortality and initial number by age class $(F$ and $N)$. In the case that the user only has the matrix $C$ (by gear and age), $F$ and $N$ can be reconstructed by means of a VPA on the pseudocohorts, in this case starting from the steady state.

The matrix $F$ and vector $N$ can represent a steady-state situation or not. The program allows starting up from both situations, or generating a new vector $N$ in equilibrium with $F$ and starting up from that situation.

\section{Activating and deactivating boxes}

The program allows the activation and deactivation of the boxes in several ways. This has been programmed with the purpose of isolating the processes to carry out confirmations or analysis. The modalities are three:

- all the boxes activated. This is the normal operation of the program;

- box of the independent stock activated. This allows simulation of the dynamics of the stock in its virgin state without the intervention of fishing (can be useful for checking balance situations or testing recruitment functions);

- one or two boxes are blocked so that they give a constant answer. 
TABLE 3. - Initial conditions for biological parameters.

\begin{tabular}{|c|c|c|c|c|c|}
\hline \multicolumn{3}{|c|}{$\begin{array}{l}\text { Length-Weight relationship } \\
\qquad \begin{array}{c}\mathrm{a}=0.0069 \\
\mathrm{~b}=3.03\end{array}\end{array}$} & \multicolumn{3}{|c|}{$\begin{array}{l}\text { Von Bertalanffy growth equation } \\
\mathrm{L} \text { inf }(\mathrm{cm})=86.8 \\
\mathrm{k}\left(\text { years }^{-1}\right)=0.137 \\
\text { to (years })=-0.367\end{array}$} \\
\hline \multicolumn{6}{|c|}{ Maturity scale } \\
\hline age & age $1=0$ & age $2=0.08$ & age $3=0.57$ & age $4=0.95$ & age $\geq 5=1$ \\
\hline \multicolumn{6}{|c|}{$\begin{array}{l}\text { Natural mortality } \quad M=0.2 \\
\text { Recruitment Beverton and Holt function: Asymptote: } 10 \text { million individuals; } S_{50 \%}: 218.943 \text { tons }\end{array}$} \\
\hline Age years & Num. ind. population & $\mathrm{F}($ trawl) & F (longline) & Catch (trawl) (tons) & Catch (longline) (tons) \\
\hline 0 & 6709272 & 0.487 & 0 & 17.26 & 0 \\
\hline 1 & 3375578 & 0.739 & 0 & 85.14 & 0 \\
\hline 2 & 1320483 & 0.459 & 0.005 & 72.69 & 0.02289 \\
\hline 3 & 683166 & 0.411 & 0.044 & 69.41 & 7.411 \\
\hline 4 & 354925 & 0.410 & 0.244 & 54.79 & 32.63 \\
\hline 5 & 151118 & 0.261 & 0.381 & 22.05 & 32.20 \\
\hline 6 & 65132 & 0.158 & 0.420 & 8.040 & 21.36 \\
\hline 7 & 29900 & 0.170 & 0.519 & 4.822 & 14.67 \\
\hline 8 & 12291 & 0.108 & 0.503 & 1.588 & 7.368 \\
\hline 9 & 5463 & 0.013 & 0.504 & 0.1047 & 4.024 \\
\hline 10 & 2668 & 0.043 & 0.458 & 0.1953 & 2.059 \\
\hline 11 & 1323 & 0 & 0.544 & 0 & 1.330 \\
\hline 12 & 629 & 0 & 0.395 & 0 & 0.5399 \\
\hline 13 & 347 & 0 & 0.204 & 0 & 0.1820 \\
\hline 14 & 232 & 0 & 0.491 & 0 & 0.2749 \\
\hline 15 & 116 & 0 & 0.433 & 0 & 0.1323 \\
\hline 16 & 62 & 0 & 0.120 & 0 & 0 \\
\hline 17 & 51 & 0 & 0.276 & 0 & 0.04327 \\
\hline 18 & 31 & 0 & 0.425 & 0 & 0.04007 \\
\hline 19 & 17 & 0 & 0.270 & 0 & 0.01510 \\
\hline
\end{tabular}

Total biomass $=808.864$ tons; $\mathrm{SSB}=499.504$ tons

\section{APPLICATION TO THE HAKE (MERLUCCIUS MERLUCCIUS) FISHERY OF CATALONIA (NW MEDITERRANEAN)}

The European hake Merluccius merluccius (L.), is one of the most commercially important demersal species in the western Mediterranean (Aldebert and Carries, 1988; Martín, 1991; Oliver and Massutí, 1995). In the Gulf of Lions, M. merluccius is the main demersal target species of the Spanish and French fishing fleets. Annual landings registered are around 3000 tons, 500 tons corresponding to the catches of the Spanish fleet (Aldebert and Recasens, 1996). Recruits and juveniles are caught with bottom trawls, and the adults mainly with French gillnets and Spanish longlines (Aldebert et al., 1993). The introduction of longlines in the 1980s (Lleonart, 1990 unpublished report, UE DG XIV, Brussels) meant a considerable increase in the exploitation of the adult stock. All assessments of NW Mediterranean hake have shown very clear symptoms of growth overfishing.

Given the commercial importance of M. merluccius, various studies have compiled biological and
TABLE 4. - Initial conditions for economic parameters. The simulations have been carried out taking into account the individual vessels; in this table only the averages of the individual vessels are presented.

\begin{tabular}{lrr}
\hline Cost structure of the fleets & Trawlers & Longliners \\
\hline Capital in $€$ / vessel & & \\
Annual insurance in $€$ / vessel & 476996 & 179042 \\
Annual costs in $€$ / vessel & 5227 & 4218 \\
Commercial costs in \% & 15377 & 12180 \\
Owner's share in \% & 19 & 19 \\
Daily ice expenses in $€$ / day & 50 & 50 \\
& 9 & 7
\end{tabular}

Technical structure of the fleets

GRT / vessel

HP / vessel

Crew / vessel

Daily fuel consumption in liters / vessel $\quad \begin{array}{rr}5 & 1052\end{array} 331$

Daily fishing hours $\quad 12.8 \quad 12.0$

Annual fishing days $\quad 200 \quad 180$

Number of vessels $\quad 16 \quad 14$

Market

Hake price in $€ / \mathrm{kg} \quad 6 \quad 6 \quad 9$

Other species

$3 \quad 15$

Other economic factors

Opportunity cost in \%

Financial cost in $\%$

Fuel price in $€ /$ liter
2
5

0.27 
fishing data from the area under study (Oliver and Massutí, 1995; Recasens et al. 1998; Morales et al. 1998). Therefore, this is a good example for showing gear interaction and its implications for a stock and the fishermen's economy. In the present application (MEFISTO) we have considered the Spanish fishery, located in the western part of the Gulf of Lions. This fleet is made up of 17 bottom trawlers and 14 longliners. Total Gross Tonnage (GT) is around 1600 for bottom trawl fleet and 210 for longline fleet.

European hake stock parameters were obtained from Aldebert et al. (1993), Aldebert and Recasens (1996). From steady state initial conditions (Table 3, biological parameters and Table 4, economic para-
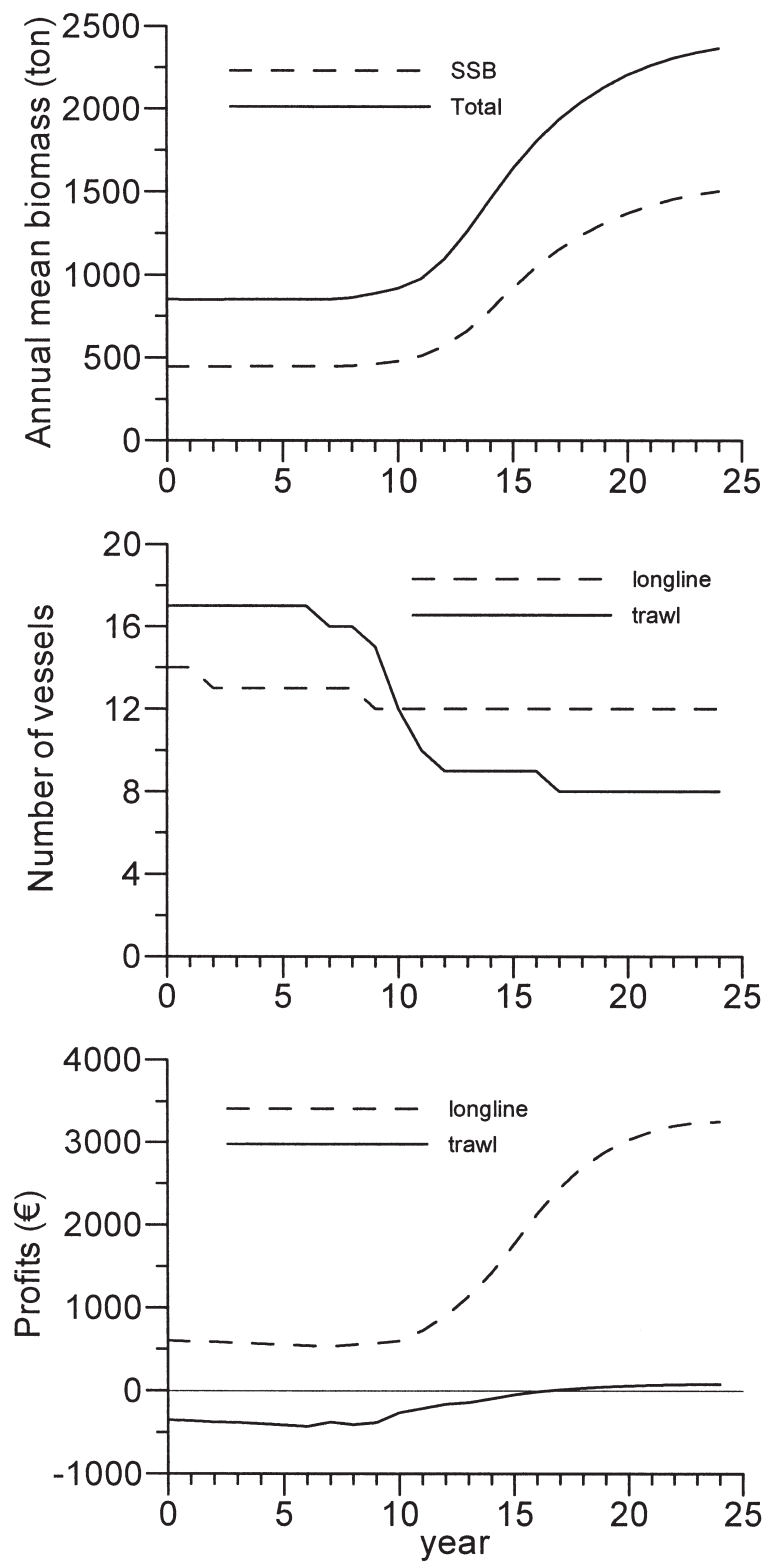

FIG. 2. - European hake stock and fishery in the initial situation. 25-year design. meters), several alternative management measures were tested through MEFISTO software. Management measures, consisting of various types of reduction of fishing effort, were selected in order to counter growth overfishing. Simulations were projected on a 25-year scenario. Three scenarios are presented, defined by different events always introduced in year 5 of the simulation.

Scenario 1: A decrease of bottom trawl fishing time, from 12.8 hours/day to 9 hours/day

Scenario 2: Trawl fleet reduction by deactivating the 3 largest trawlers.

Scenario 3: Longline fleet reduction by deactivating the 3 largest longliners.
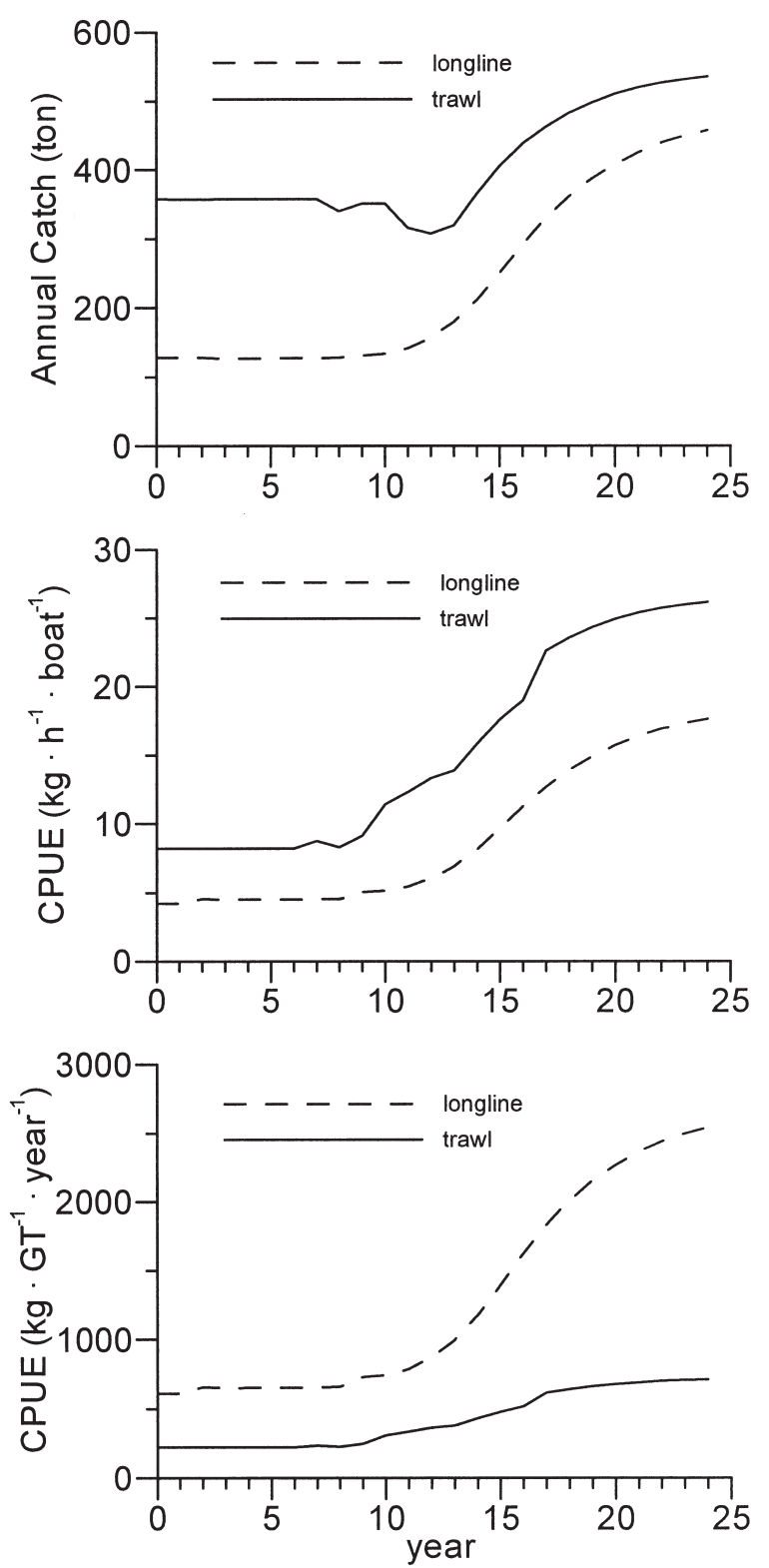

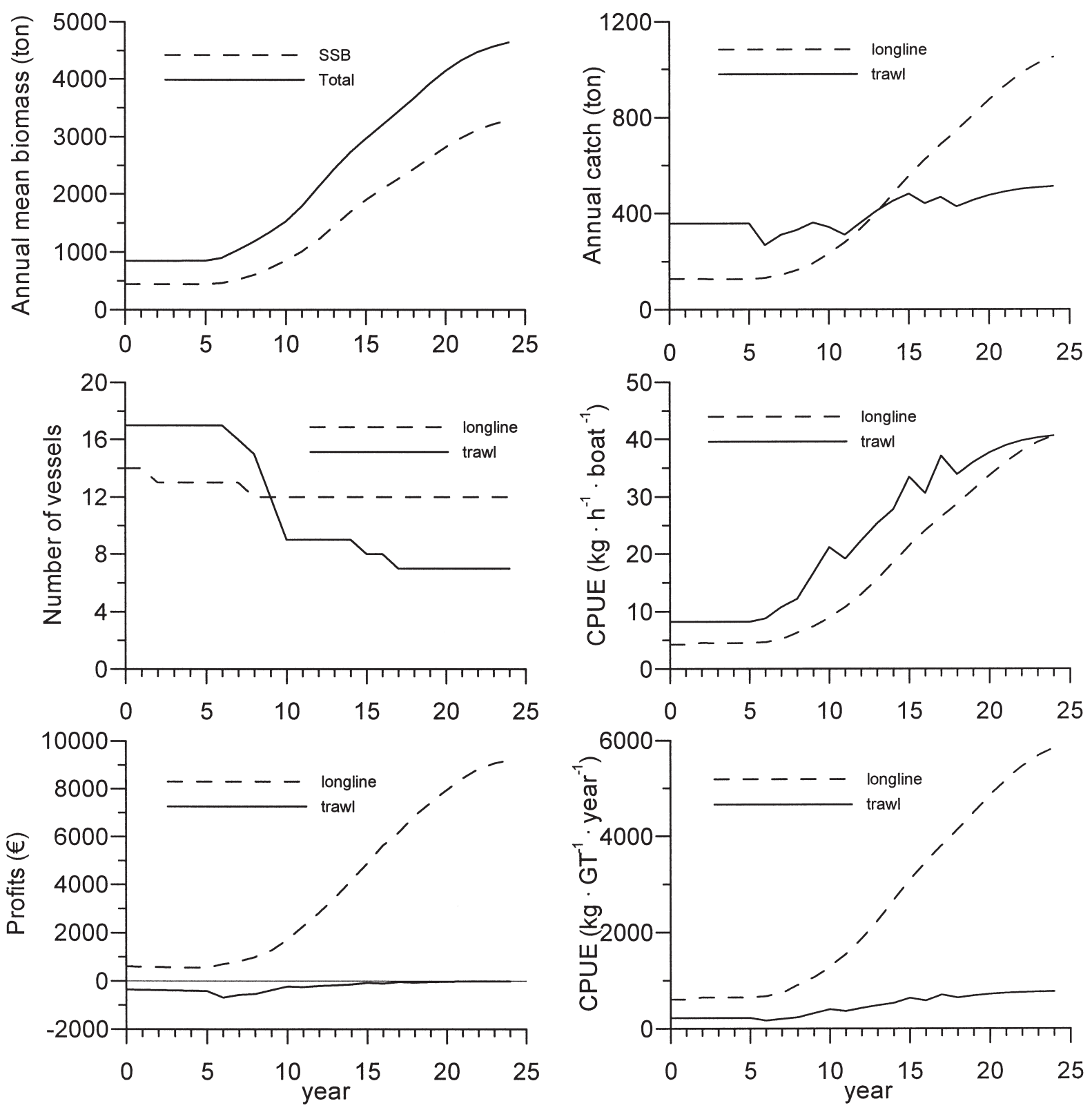

FIG. 3. - European hake stock and fishery with the event 1: reduction of fishing hours per day of the bottom trawl fleet from year $5: 12.8 \mathrm{~h} \rightarrow 9 \mathrm{~h}$.

\section{RESULTS}

Figure 2 shows the initial conditions and a 25 years projection with no management measures. Stock and catches maintain a constant value until year 8 . An increase in the stock values, catches and profits is observed from year 8 until year 25 due to decrease of the number of active boats (17 to 8 trawlers, 14 to 12 longliners). This initial situation implies that the present condition is not sustainable for fishermen without the current subsidising of the fleet, so some boats would disappear in the absence of management measures.
Figure 3 shows the effect of reduction of fishing hours per day of the trawl fleet from year 5 (scenario 1). In this case the stock shows an immediate increase. Catches for the longline show the same response and catches for the bottom trawl show a decrease between year 5 and 6 , and then an increase until reaching a level of catches higher than the initial. There is also a reduction of the trawl fleet, from the initial 17 vessels to 6 vessels. Longliners take strong advantage, while trawlers reach positive profits and increase catches at the end of the period simulated.

Figure 4 shows the effect of fleet reduction (scenarios 2 and 3). If the reduction is on the trawl fleet, 

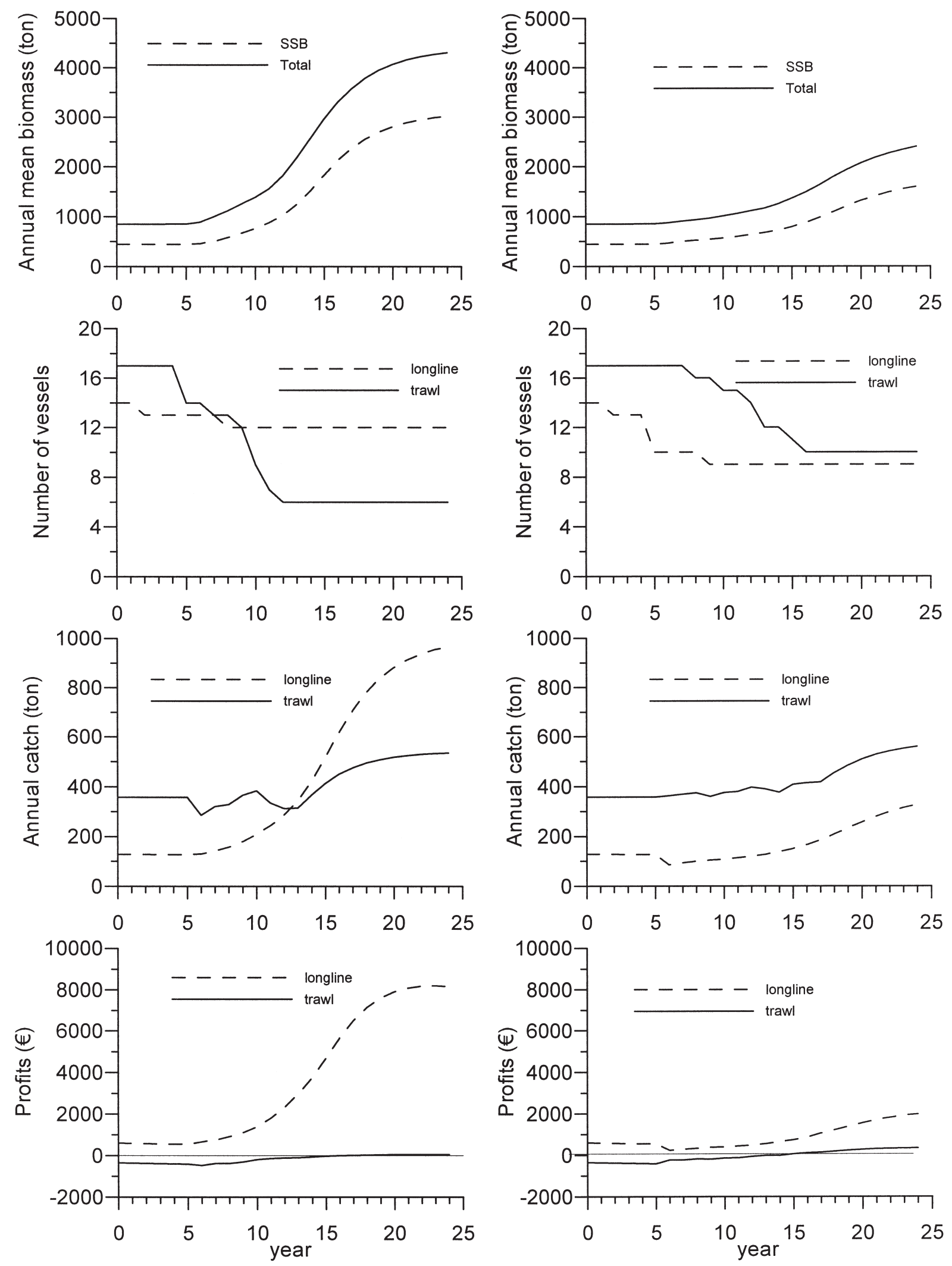

a)

b)

FIG. 4. - European hake stock and fishery with the events 2 and 3; a, event 2: reduction of the trawl fleet: deactivation of the 3 biggest trawlers; $\mathrm{b}$, event 3: reduction of the longline fleet: deactivation of the 3 biggest longliners. 
by way of deactivating the 3 largest trawlers (Fig. 4a), the stock biomass reaches a high level, while bottom trawl catches are reduced initially and then reach a higher level from year 14. Longline catches are higher and exceed the trawl catches from year 13. Results in terms of profits are clearly positive for longliners and with a slight positive trend for trawlers. On the other hand, if the reduction is on the longline fleet, by deactivating the 3 largest longliners (Fig. 4b), results for the stock are similar to figure 4a but reaching a lower level, catches show a slight increase for trawlers and for the profits, the slight positive trend is maintained.

\section{DISCUSSION}

The situation of growth overexploitation of the hake fishery in the Gulf of Lions has been stated in some papers (Aldebert et al., 1993; Aldebert and Recasens, 1996). This means that the effort is excessive or the size of the individuals caught is too low, or both. This problem is mainly generated by trawl, because the trawling fleet is larger than the longliner and the target is the smaller individuals of the stock.

The management measures tested in this paper show that due to the higher importance of the trawl compared to the longline, the most positive effect on the stock is obtained when reducing trawling. Therefore, in the Mediterranean fisheries, the controlled introduction of a fishing gear directed at the adult stock does not per se have an overly negative effect. However, the stock is more sensitive to changes that affect the juveniles. Regarding the different fleets, it has been found that trawlers do not have overall positive profits at the present status, and the current trend would be to decrease the trawler fleet, in the absence of subsidies. If the current structure of the fleets is maintained it would be better to reduce longlining, being the only case when the trawler fleet is maintained.

If the managers' objective was stock recovery, removal of trawlers or trawling effort would be the appropriate management measure. Nevertheless, if the managers' objective was to maintain the labour force (not tested here) a more appropriate measure would be to remove longlining, because it employs less people. This clearly illustrates the management conflicts between diverse objectives.

The increase in profitability in the mid-term, which arises from the management measures tested here, may in the long run cause conflicts between the fleets, as new entrants to the fishery may be encouraged, because of dormant effort.

\section{REFERENCES}

Aldebert, Y. and C. Carries. - 1988. Problèmes d'exploitation du merlu dans le golfe du Lion. FAO Rapport Pêches 395, 87-91.

Aldebert, Y. and L. Recasens. - 1996. Comparison of methods for stock assesssment of European hake Merluccius merluccius in the Gulf of Lions (Northwestern Mediterranean). Aquat. Living Resour. , 9(1): 13-22.

Aldebert, Y., L. Recasens and J. Lleonart. - 1993. Analysis of gear interactions in a hake fishery: The case of the Gulf of Lions (NW Mediterranean). In: J. Lleonart (ed.), North-western Mediterranean Fisheries. Sci. Mar., 57(2): 207-217

Annual Economic Report of European Union Fisheries, Economic Perfomance of Selected European Fishing Fleets. Concert Action FAIR PL97-3591, 2000. ISBN 90-5242-624-4, The Hague, Netherlands.

Butterworth, D.S. and M.O. Bergh. - 1993. The development of a management procedure for the South African anchovy ressource. p 83-99. In: S.J. Smith, J.J Hunt and D. Rivard (Eds.) Can. Spec. Publ. Fish. Aquat. Sci., 120.

Franquesa, R. (Coord.). - 1998. Quantitative analysis of the relation which condition the North western Mediterranean fishing system, Final Report, contract No EU-DGXIV MED/93/022, 283 pp.

Franquesa, R. - 1996. El modelo boeconómico Heures. Un instrumento para la gestión de las pesquerías basado en el control del esfuerzo. Boletín del Ministerio de Agricultura, Pesca y Alimentación, núm 34, pp 24-32, Madrid

Hannesson, R. - 1993. Bioeconomic analysis of fisheries. Fishing News Books, 138 pp

Horwood, J.W. - 1994. Modelling of fisheries management strategies. Privately published, Ministry of Agriculture, Fisheries and Food, Lowestoff (U.K.)

Lee, D.J., S.L. Larkin and C.M. Adams. - 2000, Bioeconomic Analysis of Alternative Swordfish Policies, Marine Resource Economics, Vol 15: 77-96.

Lleonart, J. (Coord.). - 1990. La pesca en Cataluña y Valencia, Descripción global y planteamiento de bases para su seguimiento. Final Report CCE DGXIV no 1989/3. 1634 pp (mimeo).

Martín, P. - 1991. La pesca en Cataluña y Valencia (NO Mediterráneo): análisis de las series históricas de captura y esfuerzo. Informes Técnicos de Scientia Marina 162: 1-43.

Morales-Nin, G.J. Torres, A. Lombarte and L. Recasens. - 1998. Otolith growth and age estimation in the European hake. J. Fish Biol., 53: 1155-1168.

OECD. - 2000. Transition to Responsible Fisheries: Economic and Policy implications. Paris.

Oliver, P.A. and E. Massutí. - 1995. Biology and fisheries of western Mediterranean hake (M. merluccius). In: Alheit, J. and Pitcher, T.J. (eds), Hake: Biology, fisheries and markets, pp. 181-202. London, Chapman and Hall.

Péredy, N., P. Guillotreau and P. Bernard. - 2000. The Impact of Prices on Seafood trade: A Panel Data Analisys of the French seafood Market. Marine Resource Economics, Vol 15: 45-66.

Pertierra, J.P. and J. Lleonart. - 1996. NW Mediterranean anchovy fisheries. Sci. Mar., 60(suppl. 2): 257-267

Punt, A.E. - 1992. Selecting management methodologies for marine ressources with an illustration for Southern African hake. S. Afr. J. Mar. Sci., 12: 943-958.

Punt, A.E. - 1993. The comparative performance of production model and ad hoc tuned VPA based feed back control management procedures for the stock of Cape hake off the West Coast of South Africa. p. 283-299. In: S.J. Smith, J.J Hunt and D. Rivard (Eds.) Can. Spec. Publ. Fish. Aquat. Sci., 120.

Recasens, L., A. Lombarte, B. Morales-Nin and G.J. Torres. - 1998. Spatiotemporal variation in the population structure of the European hake in the NW Mediterranean. J. Fish Biol., 53: 387-401.

Smit, W. - 1996. An Economic Approach to Measuring Fishing Effort: Application to a Dutch Cutter Fleet. Marine Resource Economics, 11: 305-311. 
